\title{
A RAZÃO EM ESPIRAL EM ADORNO
}

João Capistrano Filho ${ }^{1}$

\section{Resumo:}

A intenção do presente artigo é refletir sobre os caminhos que a humanidade trilhou do ponto inicial, a saber, do estado de natureza até a sociedade esclarecida. $\mathrm{O}$ artigo aborda a questão da linguagem e o seu entrosamento ao trabalho singular do homem que transforma a natureza e, por consequência, a sociedade continuamente. Aliado a esse desenvolvimento tecnológico que impulsionou a sociedade esclarecida como dominadora do homem e da natureza está à violência racionalizada que não poupa nada senão os interesses econômicos. Sob esse prisma a sociedade humana caminha em espiral bem próxima ao longo momento em que viveu sob o signo da incerteza e do medo.

Palavras-chave: Linguagem, Trabalho, Razão em espiral.

\begin{abstract}
:
The aim of this paper is thinking over the paths that the humankind have trod from the starting point, namely, from the state of nature to the enlightened society. The paper deals with the issue of language and its engagement to the man singular labor that transforms nature and, consequently, the society continuously. Allied to this technological development which propelled enlightened society as ruler of man and nature is the rationalized violence, which spares nothing but economic interests. On this view, society walks on spirals closer to the moment wherein it lived under the sign of uncertainty and fear.
\end{abstract}

Keywords: Language, Work, Spiral reason.

\section{Introdução}

Fazer uma reflexão sobre a relação entre a natureza e a sociedade humana é uma necessidade dos tempos atuais. No primeiro momento é feita uma análise da linguagem como consequência do movimento histórico impulsionado pelo trabalho singular do homem. A linguagem como expressão das realizações da humanidade no tempo histórico é o objeto pelo qual o sujeito se expressa.

\footnotetext{
${ }^{1}$ Professor de Filosofia da rede estadual de ensino do Estado do Ceará. Graduado em Filosofia pela Universidade Estadual do Ceará (UECE); Mestre em filosofia e Doutor em Educação pela Universidade Federal do Ceará (UFC).
} 
A expressão do sujeito é mediada pelo objeto, mas é pelo trabalho singular de transformar a natureza que a realidade humana em sociedade não cessa de sofrer transformações. O impulso para transformar a natureza em mercadoria está levando a ciência da tecnologia a aprimorar a exploração dos recursos como se não houvesse a possibilidade de esgotamento. A sociedade esclarecida como lembra Adorno é autoritária, ou seja, se impõe à natureza como o ditador se impõe aos homens.

A postura autoritária tem a sua origem na própria natureza quando a humanidade ainda vivia sob o seu domínio. A consciência que imaginou o mito para se relacionar com a violência do meio natural posteriormente, pela força da razão, desvelou os seus mistérios e desenvolveu a técnica. Com o desenvolvimento da técnica a humanidade encetou a caminhada para fora do círculo de dominação regido pela natureza. Essa caminhada em arcos esteve sempre sob a força de atração do modelo de existência violento herdado do mundo natural. A saída, portanto, ocorreu em espiral, a saber, a sociedade humana se desenvolveu nas cercanias daquele de quem desejava fugir: o velho mito.

\section{Trabalho e linguagem}

A realidade humana como objeto histórico é um fenômeno da natureza protagonizada pela inteligência da espécie se impondo no mundo natural sem se reconhecer parte do mesmo. Na dura e longa relação com a natureza surgiu a consciência histórica. Um fenômeno eminentemente humano. O homem é um ser biológico cuja reprodução envolve o seu corpo e por meio deste a realidade constituída pelo trabalho singular. Como entende Noam Chomsky (2008): “Trata-se de estudar a interação entre um sistema complexo e específico, dado biologicamente - a mente humana -, e o mundo físico e social”.

A linguagem humana flana na realidade histórica até se manifestar na fala em forma de som, escrita, imagem e gesto. Pela fala o sujeito se desvela no objeto. O filósofo Wittgenstein em seu livro intitulado Investigações Filosóficas demonstra a precisão de Santo Agostinho em uma passagem das Confissões:

Se os adultos nomeassem algum objeto e, ao fazê-lo, se voltassem para ele, eu percebia isto e compreendia que o objeto fora designado pelos sons que eles pronunciavam, pois eles queriam indicá-lo. Mas deduzi isto dos seus gestos, a linguagem natural de todos os povos, e da linguagem que, por meio da mímica e dos jogos com os olhos, por meio dos movimentos dos membros 
e do som da voz, indica as sensações da alma, quando esta deseja algo, ou se detém, ou recusa ou foge. (AGOSTINHO, 1991, p. 9).

Para Wittgenstein, a passagem expressa uma determinada imagem da linguagem humana representando a realidade por meio das palavras. Estas, por sua vez denominam os objetos que se interligam entre si para formar frases e organizar as ideias.

As palavras assim como aquilo que elas nominam têm a sua origem na necessidade constante de transformar a natureza. A expressão dessa relação é o trabalho humano em qualquer época. Desde os primórdios além das feras os homens enfrentavam a abundancia e a escassez na luta pela sobrevivência. Saltando para as sociedades modernas e complexas as feras são os próprios homens que dirigem o sistema de produção provocando escassez ou abundância de acordo com a necessidade de lucrar cada vez mais números na conta corrente. O objeto como realidade é composto de ações humanas entrelaçadas e transfiguradas pelo tempo, a saber, pelos afazeres que transforma a sociedade e, consequentemente, o próprio trabalho e a linguagem. Até a crença em melhores dias que, em muitos casos, guarda uma influência da religião popular tem como pano de fundo uma expectativa relacionada ao trabalho.

Para o sujeito, em estado de natureza, a cena das primeiras ameaças à sobrevivência da espécie causadas pela quebra de repetição do ciclo natural das estações despertou interrogações cujas respostas passavam pela necessidade de apaziguar os fenômenos vistos como entes metafísicos. A natureza que provera por meio do esforço árduo era a mesma que podia deixar sem nada. Os fenômenos, portanto, tinham o desejo de não somente prover, mas também de receber. Surgem então os ritos para os rios, as arvores e as montanhas tidos como entes dotados de ânimas, ou seja, de espíritos que mimavam aqueles que trabalhavam nas perigosas caçadas e os castigavam com escassez e toda sorte de sofrimentos em outros momentos.

O homem transformou o ente natural em mito e passou a venerá-lo como algo cuja existência estava imbricada à sua própria vida. A palavra não representava a coisa, mas era a coisa em si. Para Adorno, nesse momento da existência primitiva, o objeto e o sujeito existiam de modo indiferenciado por não ter ainda a humanidade aberto os olhos da autoconsciência.

A indiferenciação entre sujeito e objeto nos primórdios do processo civilizatório submetia o homem ao medo e a angústia advinda da perene incerteza. No decorrer do tempo histórico a saída para enfrentar o poder da natureza foi o desenvolvimento da técnica. A sociedade humana acompanhada da técnica como instrumento de

\begin{tabular}{|l|l|l|l|l|} 
Revista Dialectus & Ano 1 & n. 2 & Janeiro-Junho 2013 & p. 153-164 \\
\hline
\end{tabular}


sobrevivência adquire complexidade e aos poucos sai da primária divisão de trabalho por gênero.

A divisão de trabalho se expande entre aqueles que trabalham diretamente para prover a sociedade enquanto outros administram o resultado da produção e os assuntos religiosos. Os administradores da sociedade, na aurora de sua complexidade, estão ligados aos assuntos religiosos e até se confundem. Nesse estágio a palavra já deixa de se confundir com a coisa e o mito como representação começa a se institucionalizar como instrumento de controle social.

O episódio de Ulisses e as sereias na Dialética do Esclarecimento de Adorno e Horkheimer tenta mostrar essa cisão entre a natureza ainda dominadora por meio do mito e um astuto Ulisses disposto a ludibriá-la. Ao enfrentar a sedução do canto das sereias tapando os ouvidos dos marinheiros de cera enquanto ordena que estes o amarrem ao mastro para ouvir e não sucumbir, Ulisses já demonstra que a resolução dos negócios passa pela necessidade de desafiar o mito. Para os dois autores Ulisses é o protótipo da figura do burguês que se impõe à natureza dessacralizando-a e aplicando um modelo de racionalidade que atinge seu ápice muitos séculos depois.

Os marinheiros de Ulisses com os ouvidos vedados trabalham alheios ao perigo iminente, sua confiança está depositada no chefe que ouve o canto fatal, mas sai incólume. A natureza derrotada, mas fonte de tudo agora é somente um objeto e Ulisses como "solitário astucioso já é o homo oeconomicus, ao qual se assemelham todos os seres racionais: por isso, a Odisséia já é uma robinsonata" (ADORNO; HORKHEIMER 1996, p. 66).

Antes a subjetividade inconsciente se entregava a natureza, mas ao abrir os olhos da consciência se afasta dela reificando a relação entre sujeito e objeto. A natureza reificada passa a ter como único propósito a sua transformação em bens de utilidade e mercadoria. No sistema social gerido pelo fetiche da mercadoria as relações de troca não ficam somente na permuta entre bens manufaturados e dinheiro, mas envolve as pessoas cujo valor na sociedade moderna está vinculado a sua capacidade de compra.

$\mathrm{O}$ fetiche da mercadoria do sistema de produção capitalista produz a imagem social dos indivíduos. À medida que o sujeito compra o produto sua imagem social está agregada ao período de validade do mesmo. Cria-se, portanto, uma necessidade permanente de consumir o que a indústria promete para o futuro. Como escreveu Marx: "Cada homem especula sobre a maneira como criar no outro uma nova necessidade para 
o forçar a novo sacrifício, o colocar em nova dependência, para o atrair à uma nova espécie de prazer e, desse modo, à ruína”. (MARX, s/d, p. 207).

Manter o sujeito em um permanente estado de carência é o que faz da sociedade dominada pelo capitalismo um lugar de incertezas e angústias. A luta pela sobrevivência faz da sociedade dirigida pelo capital um lugar onde a tecnologia se desenvolveu como em nenhum outro tempo, mas a racionalidade responsável pelo grande salto não conseguiu escapar do modelo selvagem de existência.

Para Engels a vantagem dos homens sobre os outros animais está no fato sermos perfectíveis. O fato de sermos perfectíveis nos faz dominadores do meio em que vivemos. Mesmo aqueles que vivem ainda dependendo de modo direto da natureza, ou seja, ainda vivem no estado de natureza domina o meio como nenhuma outra espécie. A força da inteligência humana deixa sem chances qualquer espécie que por desventura se transformou em alvo para se tornar meio imediato de sobrevivência ou mercadoria.

A sociedade cujo poder se assenta na alta tecnologia manifestada nas comunicações, agricultura, indústria e força militar se lança facilmente sobre os agrupamentos mais frágeis e aqueles cujo modelo de existência está ligado a outros valores. A força militar e a grande indústria financiadora da indústria cultural imperialista suprassume a realidade do outro anulando suas perspectivas enquanto faz uso da linguagem mitigada do salvacionismo e da conservação do dominado. Assim o sujeito dominado passa a ser mediado pelas necessidades impostas pelo objeto como realidade mais poderoso, mas nada disso ocorre sem resistências e conflitos, por isso a força militar é tão essencial para a saga imperialista.

\section{O movimento do sujeito em espiral no objeto}

A existência do sujeito é consubstanciada em conflitos ligados aos múltiplos interesses que configuram a vivência no objeto como realidade histórica. Para Adorno:

\footnotetext{
A separação entre sujeito e objeto é real e aparente: verdadeira, porque no domínio do conhecimento da separação real consegue sempre expressar o cindido da condição humana, algo que surgiu pela força; falsa, porque a separação que veio a ocorrer não pode ser hipostasiada nem transformada em invariante (ADORNO, 1995, p. 182).
}

Entende o filósofo da Escola de Frankfurt que identidade e contradição são faces da mesma moeda, ou seja, quando se discursa sobre o conceito de objeto não há como deixar de fora o sujeito. $\mathrm{O}$ momento da identidade reside no fato de, para Adorno, o sujeito também ser objeto. A contradição está no fato de o sujeito ser também objeto,

\begin{tabular}{|l|l|l|l|l|} 
Revista Dialectus & Ano 1 & n. 2 & Janeiro-Junho 2013 & p. 153-164 \\
\hline
\end{tabular}


mas só ele (o sujeito) é capaz de refletir sobre a realidade. Esse é sem dúvida um ponto obscuro na filosofia de Adorno. O verdadeiro no caso expresso pela citação é o falso, pois leva em conta o conhecimento filosófico (o idealismo) que impõe uma separação entre os dois à medida que eleva o sujeito à condição de arquiteto do real. Seguindo a analise da citação, pode-se depreender que o falso é o verdadeiro à medida que a diferença entre sujeito e objeto, ou seja, o eu do sujeito não deva ser hipostasiado para não cair no idealismo, pois isso levaria o objeto a perder sua primazia. Para ele, o sujeito também é objeto, mas com um diferencial.

A diferença fundamental entre sujeito e objeto está na subjetividade que é exclusiva do sujeito. A subjetividade é dependente, no entanto, do processo histórico que influi no modo de ser de cada sujeito em sua particularidade. Nesse sentido o sujeito media o objeto e este media o sujeito. A realidade histórica, ou seja, o objeto, como expressão do processo civilizatório no tempo é mais extenso do que o sujeito no aqui e agora. $\mathrm{O}$ sujeito, portanto, surge no objeto. Surge primeiro como rebento da natureza cuja existência é anterior a ele, portanto, isso o torna também natureza.

Mas foi pela incessante mediação entre realidade e sujeito no transcurso de inumeráveis gerações que o trabalho singular e transformador no mundo natural forjou um modelo de sociedade que se diversificou em várias partes do mundo. A multiplicidade está relacionada à capacidade de trabalhar e construir em ambientes diferentes. A difícil relação entre o sujeito e a natureza externa produziu linguagens diversas que se manifestam em diferentes culturas cuja função é ser instrumento para se relacionar, conhecer e transformar.

A constelação de comportamentos sociais oriunda de tempos primitivos constituiuse por força do isolamento e da relação entre os indivíduos e a natureza. A linguagem de cada grupo social é uma consequência do modo de vida relacionado às vicissitudes impostas pelo mundo natural e em sociedade complexa dividida em classes, pelos interesses de grupos ligados ao poder. "E, se os tipos de comportamento passam de uma classe a outra, o que decerto ocorre, o que mais os altera, radicalmente mesmo, é o isolamento maior ou menor entre elas" (ELIAS, 1994, p. 125).

O sujeito de épocas passadas mergulhado no common sense não podia perceber as mudanças desenvolvidas num longo espaço de tempo. Já na sociedade da alta tecnologia que promete o fim do isolamento tudo envelhece com muita rapidez apesar das pessoas viverem mais. O fluir do objeto no tempo é o legado da humanidade com suas gerações mortas até a atual que desfruta a vivência impulsionada pelo processo

\begin{tabular}{|l|l|l|l|l|}
\hline Revista Dialectus & Ano 1 & n. 2 & Janeiro-Junho 2013 & p. 153-164 \\
\hline
\end{tabular}


educativo espontâneo promovido pelo objeto como realidade histórica. Cada geração foi formada por grupos de indivíduos que se inter-relacionaram para a resolução dos seus interesses particulares, salvo os escravizados. O grupo é o meio indispensável para somar forças e promover a sobrevivência de cada um, em outras palavras, a união é a célula primordial do homem para enfrentar as adversidades em todas às épocas.

O trabalho transformador pelo uso da técnica praticado em conjunto foi o ponto de partida para a saída do modelo de vida circular proporcionado pelo mundo natural. $\mathrm{O}$ movimento, no entanto, não teve o sentido de uma linha reta, mas sim em espiral, no plano horizontal, ou seja, a razão ao reificar a relação entre o sujeito e a natureza levou consigo a predisposição à construção de uma sociedade dominadora e violenta inspirada na relação entre vida e morte vigente na natureza. A horizontalidade e não a ascensionalidade do movimento em espiral tem como causa o fato de a humanidade estar ombro a ombro com o seu eu primitivo e violento do círculo que lutou para sair.

Não há possibilidade de se conhecer os detalhes históricos desse movimento por conta da espessa bruma que acompanha a espécie do princípio até o agora. Como escreveu Engels, no Anti-Dhuring, há um profundo abismo entre o arco e flecha e o mundo moderno da maquinaria industrial. Enfrentar o devir da natureza marcado pela contingência sempre maior que a certeza foi uma necessidade da consciência transformadora do homem. Platão dissera por meio do seu personagem Timeu: "Em verdade, o fato é que este universo ordenado nasceu como um composto produzido pela combinação de necessidade e razão" (PLATÃO, 2012, p. 74). A mente grega de Platão é pedra angular da consciência Ocidental que se estende até o moderno Descarte na necessidade de matematizar o mundo.

Para Adorno e Horkheimer até o mito como representação já era esclarecimento, pois "o mito queria relatar, dominar, dizer a origem, mas também expor, fixar, explicar" (ADORNO; HORKHEIMMER, 1996, p. 23). O ponto indelével que marca o envolvimento do homem com a natureza por intermédio da representação mítica talvez seja o temporalmente mais longo. A saída do ponto marcado pelo domínio da natureza imposto pelos ciclos dos fenômenos - cuja não repetição significava o medo e angústiaé a reviravolta na relação de dominação da natureza sobre o homem. A reviravolta tem como causa o desenvolvimento da técnica como meio de aprimoramento do trabalho e consequentemente da organização social.

A sociedade organizada pela divisão do trabalho adquire complexidade quando se urbaniza e o mito institucionalizado como organização religiosa se transforma em fonte

\begin{tabular}{|l|l|l|l|l|}
\hline Revista Dialectus & Ano 1 & n. 2 & Janeiro-Junho 2013 & p. 153-164 \\
\hline
\end{tabular}


de poder. Os mistérios da natureza sofrem o desvelamento por conta da técnica, consequentemente, o poder do mito não se localiza mais na força dos fenômenos. A força agora está sob a égide de uma casta que administra a sociedade complexa.

A humanidade urbanizada e controlada pelos interesses particulares dos mantenedores do poder passa a se impor como instrumento de dominação da natureza e do próprio homem. Ao afastar-se da natureza e da sua antiga relação com o mito o homem sai da sua estrita dependência dos ciclos naturais e se projeta para fora do estado de natureza. Ao se projetar enceta a caminhada em espiral até o agora.

A espiral configurada pelo movimento histórico revela em seus arcos a tensão entre o sujeito que tenta se afastar completamente da natureza desvelando os seus segredos antes guardados pelos mitos e o centro da espiral onde reside a sua origem sob o domínio dos fenômenos. O afastamento é o desejo de fugir da angústia e do medo imposto pelo sistema violento vigente no mundo natural.

A tensão entre o arco em que se projeta em espiral a sociedade humana esclarecida e o passado primitivo lembra o que escreveram Adorno e Horkheimer na Dialética do Esclarecimento:

O que os homens querem aprender da natureza é como empregá-la para dominar completamente a ela e aos homens. Nada mais importa. Sem a menor consideração consigo mesmo, o esclarecimento eliminou com seu cautério o último resto de sua própria autoconsciência (ADORNO; HORKHEIMMER, 1996, p. 20).

A razão em espiral no plano horizontal administra uma sociedade inclinada a reproduzir de modo calculado a dominação pela angústia, o medo e a carência. A sociedade esclarecida do mundo globalizado é um complexo de interfaces de múltiplas vivências sociais configuradas em uma sociedade poderosa que atrai tudo para o seu domínio. Sob essa dominação temos uma crise ambiental e guerras genocidas. A reprodução racionalizada da violência mítica na sociedade esclarecida é uma regressão cujo resultado é a catástrofe.

A trajetória do progresso humano mostrou-se relevante no plano do desenvolvimento da técnica e, mais ainda, com a aplicação do conhecimento avançado sobre a técnica o que chamamos de tecnologia. $\mathrm{O}$ esclarecimento humano que tem como essência a técnica impulsionou o homem para fora do centro da espiral. A saída do centro não consolidou um progresso ascendente e qualitativo. Como revela Adorno:

Pelo contrario, o progresso seria a geração da humanidade, perspectiva que se abre pela via da extinção. Segue-se disso, como também ensina Benjamin, que o conceito de história universal é irrecuperável; ele só se manteria na medida em que fosse confiável a ilusão de uma humanidade já existente, 
internamente harmônica e em movimento ascendente uniforme (ADORNO, 1995, p. 40).

Todo o progresso alcançado pelo trabalho humano ao longo do tempo tinha como intuito caminhar para longe da incerteza. A técnica elevou o poder de organização e aguçou a capacidade de prever os efeitos dos fenômenos naturais essenciais para a sobrevivência. A organização social urbanizada e administrada racionalmente criou uma divisão de trabalho atuante por dentro de uma ampla gama de instituições cuja função é exercer um rígido controle sobre a produção e os indivíduos.

Para esse intento a sociedade esclarecida, por meio de suas instituições, lança mão da tecnologia da informação para exercer uma vigilância cerrada sobre todos. Esse cerco tecnológico violador da privacidade não cessa de progredir. A vigilância em tempos primevos vinha dos fenômenos animados pela força que tudo via para favorecer ou punir.

$\mathrm{O}$ arco que representa a fuga em espiral do objeto como história é a própria razão que rege a sociedade esclarecida no plano da tecnologia levando consigo a violência indômita do longo momento em que passou a humanidade em estado de natureza. No centro da espiral ocorreu a indiferenciação "antes que o sujeito se formasse, foi o estremecimento do cego nexo natural, o mito" (Ibidem, p.183.). A indiferenciação entre o homem e a natureza nos primórdios do processo civilizatório não significou um momento de comunhão, mas sim de dominação do mundo natural por não ter o homem ainda aberto os olhos da consciência, como analisa Adorno.

A saída do centro da espiral é a fuga da dominação utilizando os recursos do antigo dominador, ou seja, a natureza. A saída não cria o desvinculamento desejado, pois os arcos que formam o círculo aberto produzido pela caminhada histórica continuam próximos ao centro mesmo que o homem se sinta longe dele e expresse repúdio ao mito antigo tido agora como superstição.

A imagem do objeto em espiral não nos permite que abarquemos a totalidade dos fenômenos sociais como se pudéssemos conhecer toda história humana por meio de uma trilha para esse fim. O fato passado não desaparece nem está intacto no presente. Ele compõe inconscientemente o modo de ser dos indivíduos vivos que constituem a pluralidade do mundo social no presente. As pirâmides do Egito é uma declaração de que houve uma civilização que perdurou por cinco mil anos no nordeste da África, mas o estado de consciência do povo que habitou por tanto tempo aquela região não pode jamais ser resgatado a não ser como especulação historiográfica baseada nos restos 
arqueológicos. $\mathrm{O}$ arco constituído pela civilização egípcia não existe mais. Os arcos da espiral não estão no passado, mas no presente como história sedimentada.

O objeto como realidade torna-se maior do que o sujeito, como entende Adorno, pelo devir heracliteano. O devir faz da sociedade humana o lugar da mutação cujo movimento é a permanente inovação tecnológica no mundo do trabalho que revoluciona a sociedade no plano estético, nas inter-relações pessoais e, por consequência, as idiossincrasias. A longevidade do sujeito singular ou de uma geração é um pequeno ponto a frente do objeto como história ou do pensamento objetivado, como diria Hegel. Para Nietzsche o "pensamento que se torna consciência é apenas a mínima parte dele..." (NIETZSCHE, 1996, p. 201).

A espiral do tempo histórico está no presente. É a realidade composta por todos os momentos da história irreconhecíveis para a consciência, pois sofrem continuas transfigurações por força do poder que tem o homem de transformar a natureza e por consequência a sociedade.

Por não se reconhecer ente natural, mas ente divino tem a natureza a seu dispor para servi-lo como objeto qualquer. Assim sendo o homem se afasta de si mesmo e atrai contra si a própria consciência que imaginou o mito como representação da violência do mundo natural. Assim como o mito a sociedade tecnológica envolve o mundo de promessas de uma vida fácil e, ao mesmo tempo, impiedosamente explora esse mundo como se não fizesse parte dele.

A racionalidade que administra a realidade é autoritária, ou como escreveram Adorno e Horkheimer: o esclarecimento é autoritário. Tende a afastar de si qualquer contradição que ponha em questão os argumentos do poder que legitimam a dominação sobre a natureza o próprio homem. A lógica da razão dominadora, no entanto, cuida para que a maioria se mantenha ocupada na sobrevivência alienada ou ignorante pela busca do mínimo garantidor do corpo vivo.

A dominação calculada é a regressividade racionalizada da consciência à violência vivenciada antes da saída em espiral. $\mathrm{O}$ antigo mito mimetizado pela razão instrumental distancia o sujeito da suspeita de retorno à violência dos primórdios da civilização quando a humanidade não se diferenciava no mundo natural.

Para Adorno, a sociedade esclarecida mergulhou na angústia mesmo desenvolvendo as condições, por meio do progresso tecnológico, de afastar a humanidade da incerteza. A reconciliação com a natureza passa pelo cuidado que o homem deve ter consigo mesmo. $\mathrm{O}$ autocuidado passa pelo respeito ao equilíbrio que só

\begin{tabular}{|l|l|l|l|l|} 
Revista Dialectus & Ano 1 & n. 2 & Janeiro-Junho 2013 & p. 153-164 \\
\hline
\end{tabular}


se realiza quando se respeita as diferenças. A dominação da natureza e do homem pelo próprio homem não pode ocorrer senão por uma força impessoal tão poderosa como a que impulsiona o sistema do mundo natural na sua relação de vida e morte.

\section{Considerações finais}

A razão em espiral é a imagem da saída do homem do estado de natureza. A saída é constituída por arcos que expressa um modelo de sociedade cujo desígnio é fugir de uma existência pautada na angústia e no medo. A sociedade atual administrada com o apoio da alta tecnologia ainda não correspondeu ao propósito do esclarecimento que era o de libertar a humanidade da angústia e do medo. A sociedade humana a partir do desenvolvimento da técnica se diferenciou na natureza, mas não da violência imperante no mundo natural. Ao se distanciar da natureza por meio da técnica a humanidade racionalizou a dominação investindo contra a natureza e o próprio homem.

A sociedade esclarecida desvelou os segredos do mito transformando-o em conhecimento, mas todo o saber conquistado por uma ciência que avança cada vez mais não eliminou a escassez e o sofrimento. Pelo contrário, em muitos casos, a escassez existe em plena abundância, ou seja, não é mais uma escassez pela simples falta, mas pela alma dos negócios capitalistas.

A fuga em espiral da humanidade como sociedade esclarecida não se livra da força da natureza desprezada. Quanto mais à sociedade esclarecida e violenta nega a natureza mais esta arrasta o arco para o seu círculo. De volta ao círculo todo o saber reservado para a libertação da humanidade servirá para a barbárie.

\section{Referências Bibliográficas}

ADORNO, W. Dialética negativa. Rio de Janeiro: Zahar Editores, 2009.

Palavras e sinais. Tradução. Petrópolis: Vozes, 1995.

ADORNO, T. W.; HORKHEIMER, M. Dialética do esclarecimento. Rio de Janeiro: Zahar Editores, 1996.

CHOMSKY, N. Problemas do conhecimento e da liberdade. São Paulo: Record, 2008.

ELIAS, N. O processo civilizador. Rio de Janeiro: Zahar Editores, 1994.

\begin{tabular}{|l|l|l|l|l|} 
Revista Dialectus & Ano 1 & n. 2 & Janeiro-Junho 2013 & p. 153-164 \\
\hline
\end{tabular}


ENGELS, F. Anti-Duhring. São Paulo: Paz e Terra, 1990.

MARX, K. Manuscritos econômicos- Filosóficos. Lisboa: Edições 70, S/d.

NIETZSCHE, F. Schopenhauer como educador. São Paulo: Nova Cultural, 1996. (Os Pensadores). 